
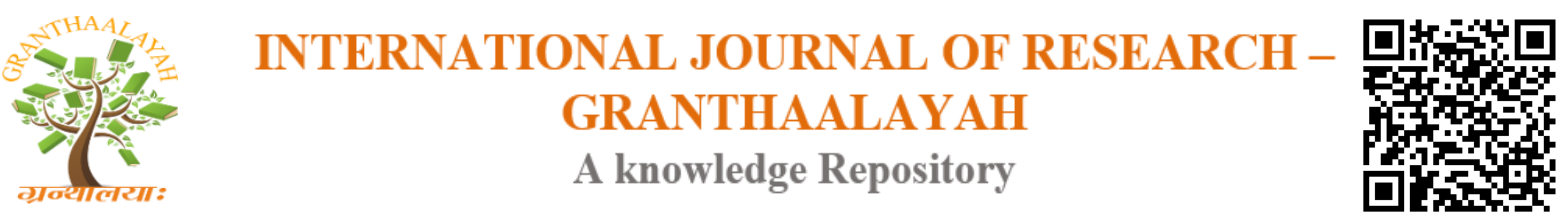

Science

\title{
DESIGN, ANALYSIS AND MANUFACTURING OF AXLE SHAFT BY ALTERNATE MATERIAL
}

\author{
Kulkarni Vipul V. ${ }^{* 1}$, Prof. Ghodake Arvind P. *2 \\ ${ }^{* 1}$ M.E. Scholar, Department of Mechanical Engineering, SND COE \& RC, Yeola Savitribai \\ Phule Pune University, Pune (M.S.) India \\ *2 Assistant Professor, Department of Mechanical Engineering, SND COE \& RC, Yeola \\ Savitribai Phule Pune University, Pune (M.S.) India
}

\begin{abstract}
This work focuses the running inconvenient weight and the weight to strength ratio of the components of the vehicle as the weight directly affects on the mileage and running cost so this is the to replace the current material by low weight material without harming the safety. In this work the axle shaft is designed and manufactured by alternate material i.e. glass fiber and epoxy resin, the objective is to replace the all components of vehicle but the representative basis is the axle of the two wheeler.

The glass fiber and epoxy resin having additional properties as they are composite materials. The composite materials i.e. composition of the more materials having properties of the all materials. The composite axle of is compared with conventional steel axle under different mechanical testing destructive and non-destructive tests with evaluating of different mechanical properties such as tensile strength, crack free structure by using appropriate experimental techniques.
\end{abstract}

Keywords: Axle; Glass Fiber and Epoxy Resin; Non-Destructive Tests; Mileage; Weight to Strength Ratio.

Cite This Article: Kulkarni Vipul V., and Prof. Ghodake Arvind P.. (2017). "DESIGN, ANALYSIS AND MANUFACTURING OF AXLE SHAFT BY ALTERNATE MATERIAL." International Journal of Research - Granthaalayah, 5(12), 200-205. https:// doi.org/10.29121/granthaalayah.v5.112.2017.493.

\section{Introduction}

In engineering i.e. automobile, civil, mechanical, naval, and aeronautical streams shafts are widely used as important element (Eg. Axles, power driving shafts, propeller shafts, steady shafts etc) and is plays key role in the same. The component is wholly dependent on properties of the material i.e. cost, strength, density etc. The shafts used currently are made of steels so the weights of these shafts are high. The properties of the steels are also limited. Cost, weight, properties are the inherent important key players in the material. The composite materials have effective and good properties of one or more materials as it is composite of more materials. Fiber 
reinforced plastics composes properties of materials are now used widely in production where it is usable to minimize mass by taking merits of their greater specific strength and stiffness. The epoxy resins and the glass fibers are the important materials as it was proved in earlier studies. In the modern period, polymers have become competent materials with traditional for different uses due to numerous competent characteristics, including light weight, easy to manufacturing and cost is also low. Therefore, efforts have been importantly made to use polymers in various manufacturing uses, using various kinds of reinforcements including fibers that are induced into the polymers to enhance their physical and mechanical properties. Thus, fiber reinforced polymer matrix composites are rigorous compatible due to light weight, bio degradability, higher strength, better stiffness, better corrosive resistant, and lower wear coefficient in different uses that are important in mechanical and tribological characteristics.

In this part we made a summary of the work done by various researchers and engineers in the field of alternate material use. Fiber reinforced plastic composes properties of all contained materials are now used widely in production where it is usable to minimize mass by taking merits of their greater specific strength and stiffness. Sam Ashworth et al. (2016) worked on "Mechanical and damping properties of resin transfer moulded jute-carbon hybrid composites", In this paper the author mentioned that hybrid composites with carbon and natural fibres offer high modulus and strength combined with low cost and the ability to damp vibration. The inclusion of carbon plies for the HFRP panel has given a useful increase in tensile strength but more significantly the tensile modulus has almost doubled. In addition, the tensile moduli for both NFRP and HFRP have shown a small increase with injection pressure. Images from optical microscopy, and results for ${ }^{[1]}$. Stephen I. Durowaye et al. (2016) worked on "Development and characterization of iron mill scale particle reinforced ceramic matrix composite". The physical characterization of a material is one of the scientific techniques that is normally employed to investigate its intrinsic properties for potential areas of application. The low porosity obtained enhances the achievement of compact and dense composite brake pad materials with the tendency to improve the mechanical properties, while relatively low linear shrinkage will ensure dimensional stability under service conditions. ${ }^{[2]}$ Emad Omrani et al. (2016) worked on "State of the art on tribological behavior of polymer matrix composites reinforced with natural fibers in the green materials world". Natural fiber reinforced polymer composites are attractive and demanding materials to replace conventional materials in order to solve critical environmental problems. This means that the inter surface plays a dominant role in tribological properties. Also, orientations of fibers are one of the factors that can affect wear and friction behavior where the best orientation to have the greatest tribological properties is normal orientation of fibers against sliding direction. Generally, the wear rate increases by increasing the applied load ${ }^{[3]}$. Kristiina Oksman et al. (2016) worked on "Review of the recent developments in cellulose nano composite processing". In this paper, this review addresses the recent developments of the processing of cellulose nanocomposites, focusing on the most common techniques, including solution casting, melt-processing of thermoplastic cellulose nanocomposites and resin impregnation of cellulose nanopapers using thermoset resins. Important techniques, such as partially dissolved cellulose nanocomposites, nanocomposite foams reinforced with cellulose nanocrystals and nanofibers, as well as long continuous fibers or filaments, are also addressed, which have great potential as future reinforcing fibers for use in biocomposites ${ }^{[4]}$. Jaswinder Singh and Amit Chauhan (2016) worked on "Characterization of hybrid aluminum matrix composites for advanced applications - a review", in this paper the some other particulates such 
as mica, B4C have also shown significant potential as a secondary reinforcement for development of hybrid composites. It has also been observed that the physical and mechanical behavior of produced composites is influenced by composition and type of the reinforcement (hard or soft). Consequently, the HAMCs can be fabricated with different combinations of reinforcements to achieve desirable mechanical properties not available in ceramic reinforced composites. The density of HAMCs increases with increasing contents of ceramic reinforcements, while incorporation of partial reinforcements like fly ash, rice husk ash, mica, etc. reduces the density of composites ${ }^{[5]}$. P Pokorný et al. (2015) worked on "Influence of threshold values on residual fatigue lifetime of railway axles under variable amplitude loading", in this study The paper deals with establishing of the residual fatigue lifetime of the railway axle with crack. The sensitivity of obtained results on the scatter of material constant $C$ is the same for both considered initial crack lengths $(1 \mathrm{~mm}$ and $2 \mathrm{~mm}$ ). The estimated residual fatigue lifetimes of the railway axles are calculated for certain probability of constant $C$ and probability of the stress intensity factor threshold value $K^{\text {th }}$. The table 1 shows calculated residual fatigue lifetimes in "load blocks" determined for the mean value of $K^{\text {th }}$ and five different linear fits determining value of material constant $C^{[6]}$.

\section{Materials and Methods}

The physical properties of composite materials are generally not isotropic (independent of direction of applied force or load) in nature, but rather are typically orthotropic (depends on the direction of the applied force or load). For instance, the stiffness of a composite panel will often depend upon the orientation of the applied forces and/or moments. Panel stiffness is also dependent on the design of the panel. In contrast, isotropic materials (for example, aluminum or steel), in standard wrought forms, typically have the same stiffness regardless of the directional orientation of the applied forces and/or moments. The material used for the manufacturing currently is steel. The experimentation made on the manufactured material by the destructive testing as well as non-destructive testing (NDT). The destructive testing is used for the checking of the strength of the object.

The non-destructive testing used for the internal structure as well as the sound velocity, crack detection as well as the feasibility of the axle. The three types of material is as described below. The axles having different properties are shown below.

\section{Traditional Steel}

The steel used in the current axle of Unicorn vehicle of honda company. The strength is the most important matter in the axle and weight is also important fact of the vehicle parts.

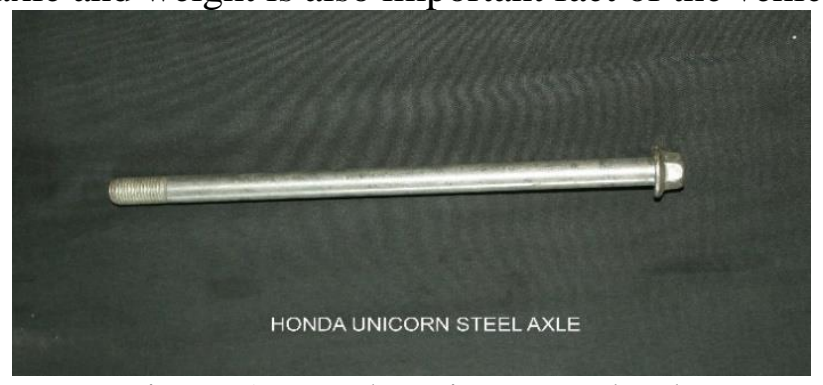

Figure 1: Honda unicorn steel axle 


\section{Epoxy Resin}

Epoxy resin is also compatible material in modern mechanical parts. It was also taken in the study.

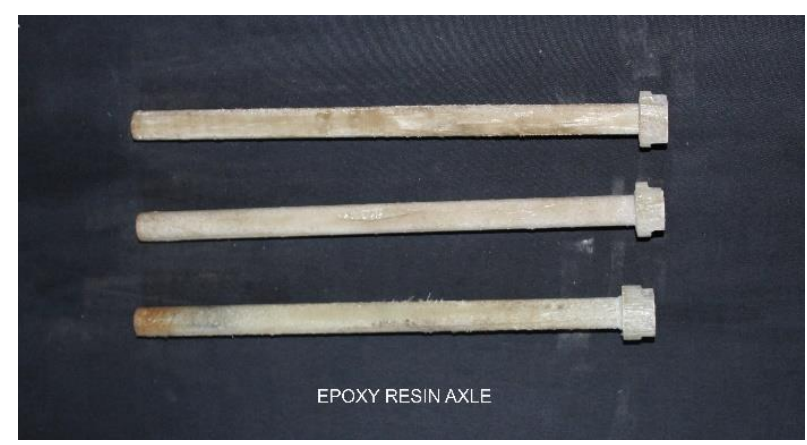

Figure 2: Epoxy resin axle

\section{Glass Fiber}

Glass fiber is a material consisting of numerous extremely fine fibers of glass. Glassmakers throughout history have experimented with glass fibers, but mass manufacture of glass fiber was only made possible with the invention of finer machine tooling.

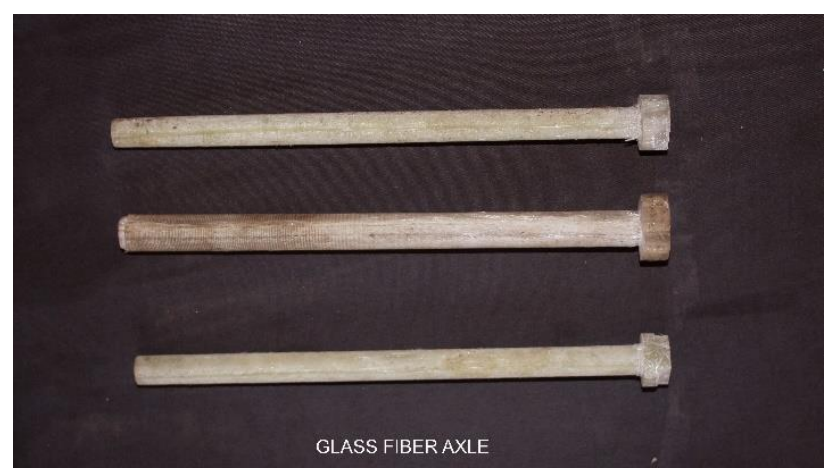

Figure 3: Glass fiber axle

\section{Experimentation}

The third stage after design and manufacture of the epoxy resin and glass fiber axle is the experimental validation. The strength and weight, crack free structure as proposed in the starting is validated by the experimental techniques. The universal testing machine is used for destructive testing for the strength evaluation. The non-destructive testing's used for the internal structure observation.

\section{Results and Discussions}

The test taken on the steel, epoxy resin and glass fiber as it was the comparative study. The destructive testing was taken on the universal testing machine. The glass fiber has better strength than epoxy resin than steel. The same study was done in the non-destructive testing. The 
ultrasonic testing was done in the NDT testing laboratory. No recordable indication was got. The result is very better than the steel within experimental limits.

The below graph shows the weight of axles in gms.

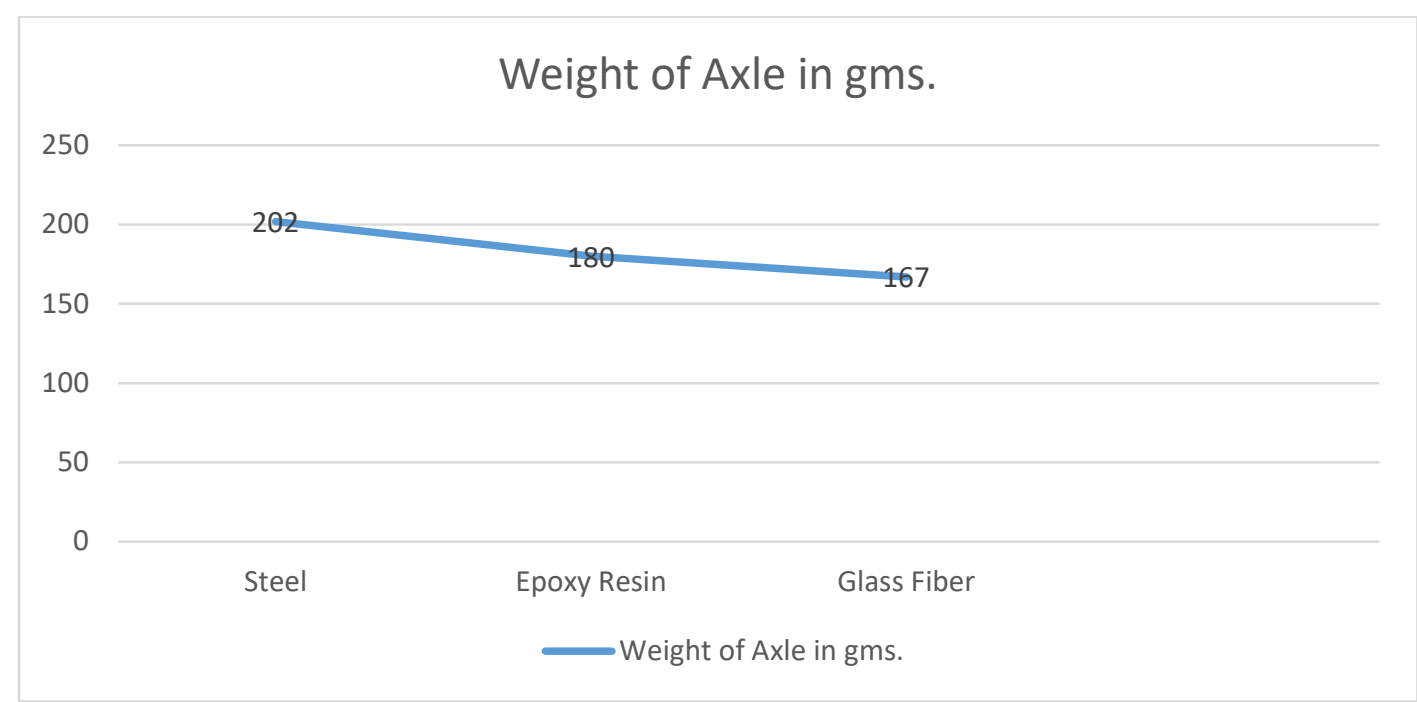

Graph 1: Weight of axle in grams

The above graph shows that the weight of steel axle was more than epoxy resin than glass fiber as the density of the steel was more than epoxy resin than glass fiber.

The below graph shows the tensile strength in Pa taken on universal testing machine.

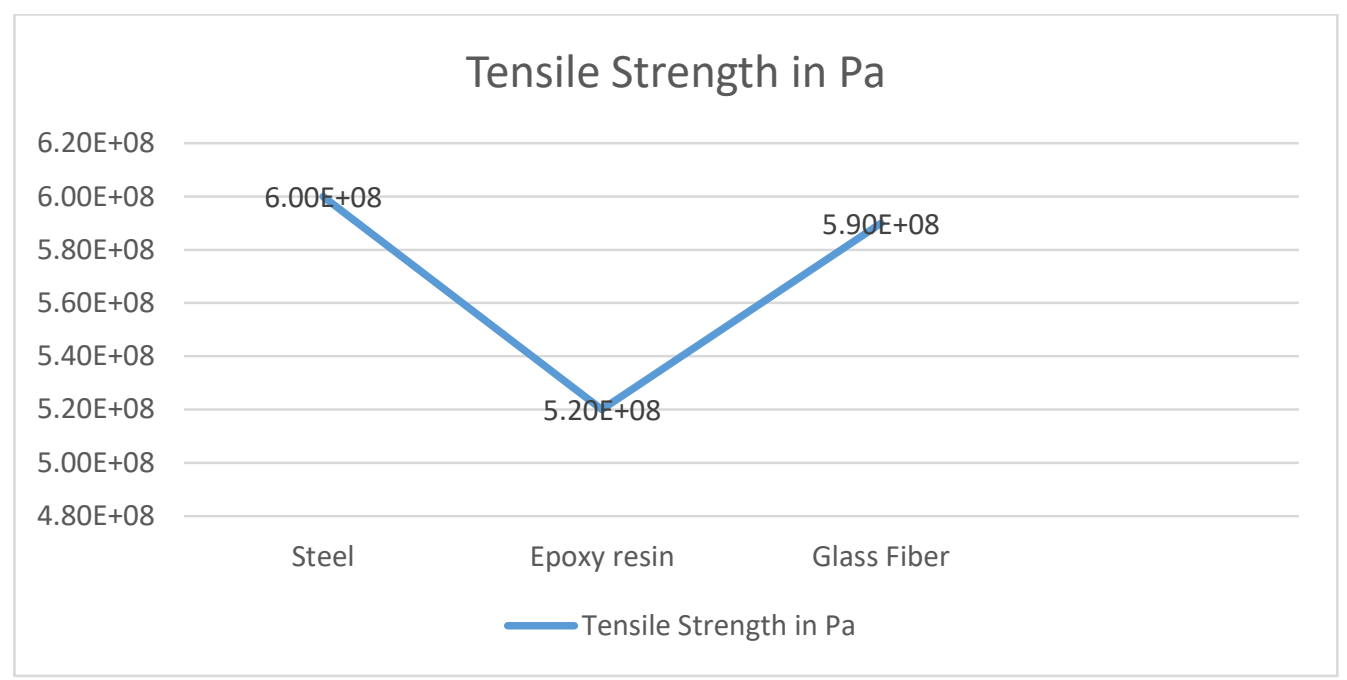

Graph 2: Tensile strength of axle in $\mathrm{Pa}$

The tensile strength of the glass fiber and epoxy resin was found slightly lower than the steel within experimental limit. The proposed work is fulfilled with this experimentation within the experimental limits. 


\section{Conclusions}

The steel is the traditional material for the axle and it can be replaced by composite materials like glass fiber or the epoxy resin. The most important factors were discussed in this thorough study. The epoxy resin is also better material but the glass fiber is the better than the epoxy resin also.

\section{Acknowledgements}

People who contributed to the work but do not fit criteria for authorship should be listed in the Acknowledgments, along with their contributions. It is advised that authors ensure that anyone named in the acknowledgments agrees to being so named. Funding sources that have supported the work should also be cited.

\section{References}

[1] Sam Ashworth, Jem Rongong, Peter Wilson, James Meredith, Mechanical and damping properties of resin transfer moulded jute-carbon hybrid composites, ELSEVIER, International Journal on Composites, 2016, 105 (1), pp. 60-66.

[2] Stephen I. Durowaye, Olatunde I. Sekunowo, Abdulganiyu I. Lawal, Olusola E. Ojo, Development and characterization of iron mill scale particle reinforced ceramic matrix composite, ELSEVIER JTUSCI, 2016, pp. 1-11.

[3] Emad Omrani, Pradeep L. Menezes, Pradeep K. Rohatgi, State of the art on tribological behavior of polymer matrix composites reinforced with natural fibers in the green materials world, ELSEVIER JESTECH, 2016, 19(1), pp. 717-736.

[4] Kristiina Oksman, Yvonne Aitomäki, Aji P. Mathew, Gilberto Siqueira, Qi Zhou, Svetla Saleh Hooshmandna Butylina, Supachok Tanpichai, Xiaojian Zhou, Review of the recent developments in cellulose nano composite processing, ELSEVIER, International Journal on Composites, 2016, A83, pp. 2-18.

[5] Jaswinder Singh and Amit Chauhan, Characterization of hybrid aluminum matrix composites for advanced applications - a review, JMR\&T 2016, 5 (2), pp. 159-169.

[6] P Pokorný, P, Náhlík, L, Hutar, P, Influence of threshold values on residual fatigue lifetime of railway axles under variable amplitude loading, ELSEVIER Procedia Engineering, 2015, 101, pp. 380-385.

*Corresponding author.

E-mail address: vipulkulkarni76@ gmail.com 